\title{
OPTIMALISASI PENGGUNAAN MODA ANGKUTAN BUS TRANS LAMPUNG DALAM PENINGKATAN KONEKTIVITAS TRANSPORTASI WISATA KAWASAN TELUK LAMPUNG
}

\author{
Muhammad Zainal Ibad ${ }^{1}$, Ayu Fitriyani' ${ }^{1}$, Rahayu Sulistyorini² \\ ${ }^{1}$ Institut Teknologi Sumatera, Jl. Terusan Ryacudu, Way Huwi, Lampung Selatan \\ ${ }^{2}$ Universitas Lampung, Jl. Prof. Dr. Ir. Sumantri Brojonegoro No.1, Kota Bandar Lampung, Lampung \\ ${ }^{1}$ Email : zainal.ibad@pwk.itera.ac.id \\ DOI: 10.35472/jppk.v1i1.603
}

\begin{abstract}
Pesawaran Regency is known to have advantages in the tourism sector. This can be seen from the number of tourists who continue to increase, especially on national holidays. The Provincial Government is collaborating with the Trans Lampung Bus by opening routes to tourist destinations, namely from Tanjung Karang Station - Ketapang Harbor. However, in practice, there is a tendency for tourists to use private transportation modes compared to public transportation modes that have been provided. Therefore, this study aims to find out how to increase tourist interest in using the Trans Lampung Bus public transportation route from Tanjung Karang Station to Ketapang Port as tourist transportation. There are three targets to achieve the research objectives, namely: 1. Knowing what factors influence the choice of mode; 2. Knowing the opportunities for using private and public transportation modes; 3. Make recommendations for optimizing public transportation mode. The analytical method used in this study is binary logistic regression and sensitivity. Based on the sensitivity analysis, it is known that the comfort factor has a higher sensitivity than the bus trip rit factor. Therefore, the comfort factor will be optimized first.
\end{abstract}

Keywords: Mode Selection, Tourist Transportation, Binary Logistic Regression, Sensitivity, Public Transport

\section{A. PENDAHULUAN}

Kabupaten Pesawaran memiliki garis pantai mencapai 96 km, sehingga pemerintah mendorong Kabupaten Pesawaran untuk menjadi daerah yang memiliki keunggulan pada sektor pariwisata. Adanya Peraturan Pemerintah (PP) nomor 38 Tahun 2017 tentang inovasi daerah membuat pemerintah Kabupaten Pesawaran berencana untuk membuat Kawasan Ekonomi Khusus (KEK) Pariwisata Teluk Pandan yang terletak di Kecamatan Teluk Pandan. Terdapat arahan pengembangan pariwisata di Kabupaten Pesawaran yang tertuang di dalam Rencana Pembangunan Jangka Menengah Daerah (RPJMD) 2016 2022 dan Rencana Induk Pengembangan Pariwisata Daerah (RIPPDA) Kabupaten Pesawaran 2017 - 2031

Terus meningkatnya jumlah wisatawan terutama pada waktu tertentu seperti saat hari raya besar atau sebagainya, menyebabkan terjadinya kemacetan pada jalur utama menuju tempat wisata. Salah satu upaya yang yang dilakukan Pemerintah Provinsi untuk menekan pergerakkan lalu lintas perkotaan adalah menyediakan moda angkutan umum. Hal tersebut bertujuan agar pariwisata di provinsi lampung terus berkembang namun 
tidak menimbulkan permasalahan baru seperti kemacetan. Pemerintah Provinsi bekerjasama dengan PT. Lampung Jasa Utama (LJU) pengelola bus trans lampung untuk membuka rute menuju destinasi wisata. Rute tersebut memiliki titik keberangkatan Stasiun Tanjung Karang dan titik pemberhentian di Pelabuhan Ketapang. Rute tersebut merupakan satu dari enam rute Bus Trans Lampung yang sudah beroperasi. Pembukaan rute bus tersebut merupakan salah satu program dari Pemerintah Provinsi Lampung yang menginginkan agar trans lampung fokus kepada pengembangan transportasi pariwisata dan transportasi publik (Saputra, 2017).

Namun dalam praktiknya, wisatawan memiliki kecenderungan menggunakan moda angkutan pribadi dibandingkan dengan moda angkutan umum Bus Trans Lampung sebagai transportasi menuju destinasi wisata. Permasalahan dalam pemilihan moda transportasi dapat dikatakan sebagai salah satu tahapan terpenting dalam berbagai perencanaan dan kebijakan transportasi. Hal tersebut menyangkut efisiensi pergerakkan di wilayah perkotaan, dimana didalamnya terdapat ruang yang harus disediakan kota untuk dijadikan transportasi dan banyaknya moda transportasi yang dapat dipilih oleh penduduk (Tamin, 2008). Penyebab pengunjung lebih memilih menggunakan moda transportasi pribadi dibandingkan dengan moda transportasi umum diduga berkaitan dengan kualitas pelayanan Bus Trans Lampung. Kualitas pelayanan merupakan suatu kondisi atau karakteristik dari moda angkutan umum yang diharapkan oleh pengguna, terdiri dari beberapa hal yaitu keselamatan, kemudahan pencapaian, keandalan, perbandingan biaya dan efisiensi (Anggoman, 2007). Pelayanan Bus Trans Lampung rute Stasiun Tanjung Karang - Pelabuhan Ketapang yang belum memenuhi kriteria-kriteria yang diharapkan oleh wisatawan tersebut diduga menjadi penyebab kurangnya minat dalam menggunakan moda angkutan umum. Oleh karena itu, perlu dilakukannya studi mengenai cara untuk meningkatkan minat wisatawan dalam menggunakan moda angkutan umum Bus Trans Lampung.

Penelitian ini bertujuan untuk mengetahui bagaimana cara meningkatkan minat masyarakat dalam menggunakan moda angkutan umum Bus Trans Lampung rute Stasiun Tanjung Karang - Pelabuhan Ketapang sebagai transportasi wisata. Tujuan tersebut dapat dicapai melalui sasaran-sasaran sebagai berikut yaitu:

1. Mengetahui faktor-faktor apa yang mempengaruhi dalam pemilihan moda

2. Mengetahui peluang penggunanaan moda angkutan pribadi dan umum

3. Membuat rekomendasi pengoptimalan penggunaan moda angkutan umum Bus Trans Lampung. Penelitian ini akan terfokus pada tempat wisata yang dapat dijangkau oleh Bus Trans Lampung rute Stasiun Tanjung Karang - Pelabuhan Ketapang.

\section{B. METODE PENELITIAN}

Metode pengumpulan data yang digunakan dalam penelitian ini meliputi survei primer dan sekunder. Pengumpulan data primer dilakukan melalui kuisioner menggunakan teknik stated preference. Kuisioner tersebut disebarkan secara online dan responden yang dapat mengisi kuisioner tersebut adalah responden yang sudah pernah melakukan kunjungan wisata ke objek wisata yang dilewati oleh Bus Trans Lampung 
Stasiun Tanjung Karang - Pelabuhan Ketapang. Pengumpulan data sekunder dilakukan dengan survei instansional ke PT. Lampung Jasa Utama.

Adapun ciri-ciri dari teknik stated preference ini adalah adanya penggunaan rancangan eksperimen untuk membangun alternatif hipotesis terhadap situasi (hypothetical situation) yang kemudian disajikan kepada responden (Rahman, 2009). Dalam penelitian ini preferensi responden dikuantifikasikan berdasarkan pilihan dan peringkat (rating) dengan rentang nilai yang diberikan adalah 1-10, dimana nilai 1 berarti sangat buruk dan nilai 10 berarti sangat baik. Survei instansional dilakukan untuk mendapatkan data pendukung dalam penelitian ini. Adapun perhitungan jumlah responden yang dilakukan menggunakan rumus slovin, yaitu:

$$
\begin{gathered}
n=\frac{N}{1+N e^{2}} \\
n=\frac{798.173}{1+798.173(0,1)^{2}}=99,98
\end{gathered}
$$

Berdasarkan perhitungan di atas maka dapat diketahui bahwa jumlah sampel yang digunakan dalam penelitian ini adalah 99,98 yang dibulatkan menjadi 100 responden. Terdapat dua analisis yang digunakan dalam penelitian ini yaitu analisis regresi logistik dan analisis sensitivitas. Analisis menggunakan model binomial logit dalam penelitian ini dilakukan untuk mengetahui hubungan antara variabel terikat (variabel dependen) yang berupa biner dan variabel bebasnya yang berupa skala interval atau kategori. Variabel biner hanya mempunyai dua kemungkinan nilai yang biasanya dinyatakan dengan 0 (tidak berhasil) dan 1 (berhasil).

Dalam penelitian ini kejadian dikatakan berhasil apabila wisatawan bersedia menggunakan moda angkutan umum. Oleh karena itu, bilangan biner 1 menyatakan moda angkutan umum Bus Trans Lampung, sedangkan variabel bebas merupakan faktor-faktor yang akan dikaji dalam upaya meningkatkan minat wisatawan untuk menggunakan moda angkutan umum. Faktor-faktor tersebut didapat dari sintesis faktor pada penelitian terdahulu. Analisis sensitivitas bertujuan untuk mengetahui pergeseran perubahan nilai peluang pemilihan moda angkutan pribadi ke moda angkutan umum Bus Trans Lampung jika dilakukan perubahan atribut pada pelayanannya.

\section{HASIL DAN PEMBAHASAN}

Uji validitas dan uji reabilitas digunakan untuk melihat apakah data dapat digunakan/dilanjutkan ke analisis selanjutnya. Untuk mengetahui keaslian data (reabilitas) dilihat berdasarkan P-Value pada Hosmer-Lemeshow test (Putri, 2018) Uji validitas digunakan untuk melihat kevalidan data yang digunakan dalam penelitian dengan menggunakan $P$-Value pada Pearson Test. Syarat nilai $P$-Value $\geq 0,05$, sedangkan syarat untuk Hosmer-Lemeshow test adalah $P$-Value $<0,2$ yang berarti sangat rendah, 0,2 $<P$-Value $<0,4$ artinya rendah, $0,4<P$-Value $<0,7$ artinya sedang, $0,7<P$-Value $<0,9$ artinya tinggi dan $0,9<P$-Value $<1,0$ memiliki arti sangat tinggi (Basuki, 2015). Dalam 
penelitian ini didapatkan $P$-Value sebesar 0,855 yang artinya data dalam penelitian ini valid, sedangkan P-Value dari Hosmer-Lemeshow test sebesar 0,985, artinya reabilitas data pada penelitian ini sangat tinggi.

Berdasarkan hasil perhitungan software MiniTAB diketahui bahwa dari 16 faktor yang diteliti dalam penelitian ini, terdapat 2 (dua) faktor yang paling memengaruhi dalam pemilihan moda yaitu X10 yang merupakan faktor kenyamanan dan X16 yang merupakan rit perjalanan bus. Kedua faktor tersebut terdapat didalam persamaan utilitas yang didapatkan dari hasil oleh MiniTAB. Hasil perhitungan menggunakan MiniTAB 17 didapatkan nilai koefisien determinasi $\mathrm{R}^{2}$ sebesar $63,89 \%$. Semakin besar nilai $\mathrm{R} 2$ maka semakin kuat kemampuan model yang diperoleh untuk menerangkan kondisi yang sebenarnya (O.Z, 2008). Oleh karena itu, faktor kenyamanan dan rit perjalanan dapat menjelaskan faktor pemilihan moda angkutan umum Bus Trans Lampung Stasiun Tanjung Karang - Pelabuhan Ketapang sebesar 63,89\%, sedangkan sisanya sebesar $31,11 \%$ dijelaskan oleh variabel bebas lainnya.

$$
U_{T}=-14.53+2.249 X 10+0.745 X 16
$$

\section{Keterangan:}

UT = Nilai Utilitas Moda Angkutan Umum Bus Trans Lampung

X10 $=$ Kenyamanan Moda Angkutan Umum Bus Trans Lampung

X16 $=$ Rit perjalanan Moda Angkutan Umum Bus Trans Lampung

Setelah diketahui persamaan utilitas, maka selanjutnya dapat diketahui model peluang dari masing-masing moda angkutan umum, yaitu:

$$
\begin{gathered}
\mathrm{P}_{\text {Umum }}=\frac{\operatorname{Exp}\left(\mathrm{U}_{\mathrm{T}}\right)}{1+\operatorname{Exp}\left(\mathrm{U}_{\mathrm{T}}\right)} \\
\mathrm{P}_{\text {Pribadi }}=1-\mathrm{P}_{\text {Umum }}
\end{gathered}
$$

Keterangan:

$\mathrm{P}_{\text {Pribadi }}=$ Peluang Pemilihan Moda Angkutan Umum

$\mathrm{P}_{\text {Umum }} \quad=$ Peluang Pemilihan Moda Angkutan Pribadi

$\mathrm{U}_{\mathrm{T}}=$ Nilai Utilitas Moda Angkutan Umum Bus Trans Lampung

Sudah didapatkannya peluang masing-masing dari moda angkutan, langkah selanjutnya adalah melakukan analisis sensitivitas. Analisis sensitivitas dilakukan untuk mengetahui dan memahami perubahan nilai dari peluang pemilihan moda angkutan pribadi ke pemilihan moda angkutan umum Bus Trans Lampung apabila dilakukan perubahan pada pelayanannya berdasarkan faktor-faktor yang paling memengaruhi. Setelah dilakukan analisis sensitivitas, didapatkan beberapa skenario yang dapat dilihat sebagai berikut: 


\section{a. Perubahan peluang kenyamanan}

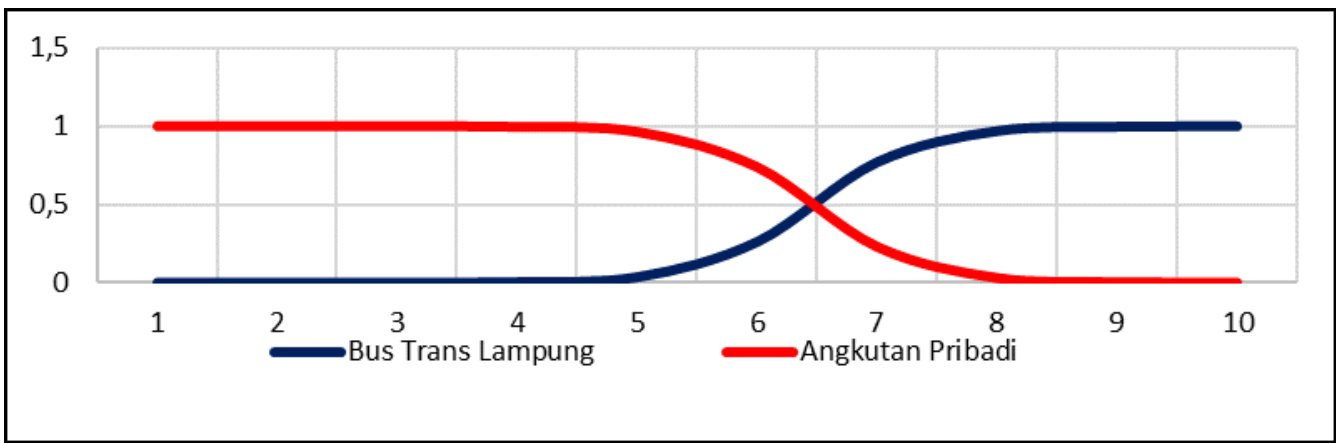

Sumber : Penulis, 2019

Gambar 1. Skenario Perubahan Peluang Kenyamanan pada Moda Angkutan Umum Bus Trans Lampung dan Moda Angkutan Pribadi

Berdasarkan gambar di atas yang didapatkan dari hasil perhitungan diketahui bahwa wisatawan bersedia beralih menggunakan Bus Trans Lampung sebagai transportaso pariwisata jika kenyamanan yang diberikan oleh moda angkutan umum tersebut bernilai lebih dari tujuh. Hal tersebut terlihat dari nilai perpotongan yang terjadi pada Gambar 1.

\section{b. Perubahan peluang kenyamanan}

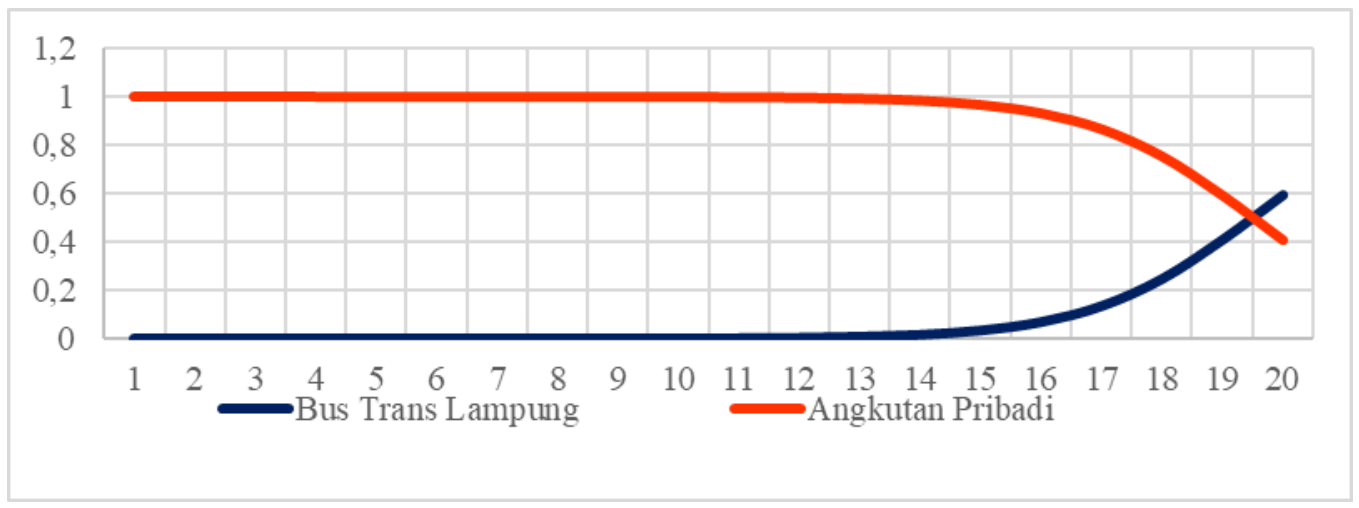

Sumber : Penulis, 2019

Gambar 2. Skenario Perubahan Peluang Rit Perjalanan Bus pada Moda Angkutan Umum Bus Trans Lampung dan Moda Angkutan Pribadi

Setelah itu dilakukan perhitungan perubahan peluang pada faktor lain yang memengaruhi yaitu rit perjalan bus. Dapat di lihat pada Gambar 2. bahwa titik perpotongan terjadi pada nilai lebih dari 19, artinya bahwa wisatawan baru bersedia beralih menggunakan moda angkutan umum yaitu Bus Trans Lampung jika rit perjalanan bus yang dilakukan sangat banyak.

\section{Analisis Sensitivitas}


Analisis ini dilakukan untuk mengetahui perubahan atau pergeseran nilai peluang dari moda angkutan pribadi ke moda angkutan umum jika dilakukan perubahan nilai pada faktor pemilihan moda angkutan umum Bus Trans Lampung, berdasarkan faktor yang paling berpengaruh. Output dari analisis ini akan digunakan untuk mengetahui bagaimana pengoptimalan moda angkutan umum Bus Trans Lampung. Analisis sensitivitas yang akan dilakukan oertama yaitu faktor kenyamanan terhadap rit perjalanan ini, hal tersebut dimaksudkan bahwa ketika kenyamanan yang disediakan oleh Bus Trans Lampung sebesar sekian, maka dibutuhkan angka nilai berapa untuk membuat wisatawan bersedia menggunakan Bus Trans Lampung dibandingkan dengan moda angkutan pribadi. Keenam skenario tersebut akan dijadikan sebagai bahan pertimbangan untuk membuat rekomendasi pengoptimalan. Skenario tersebut dapat dilihat pada Gambar 3.

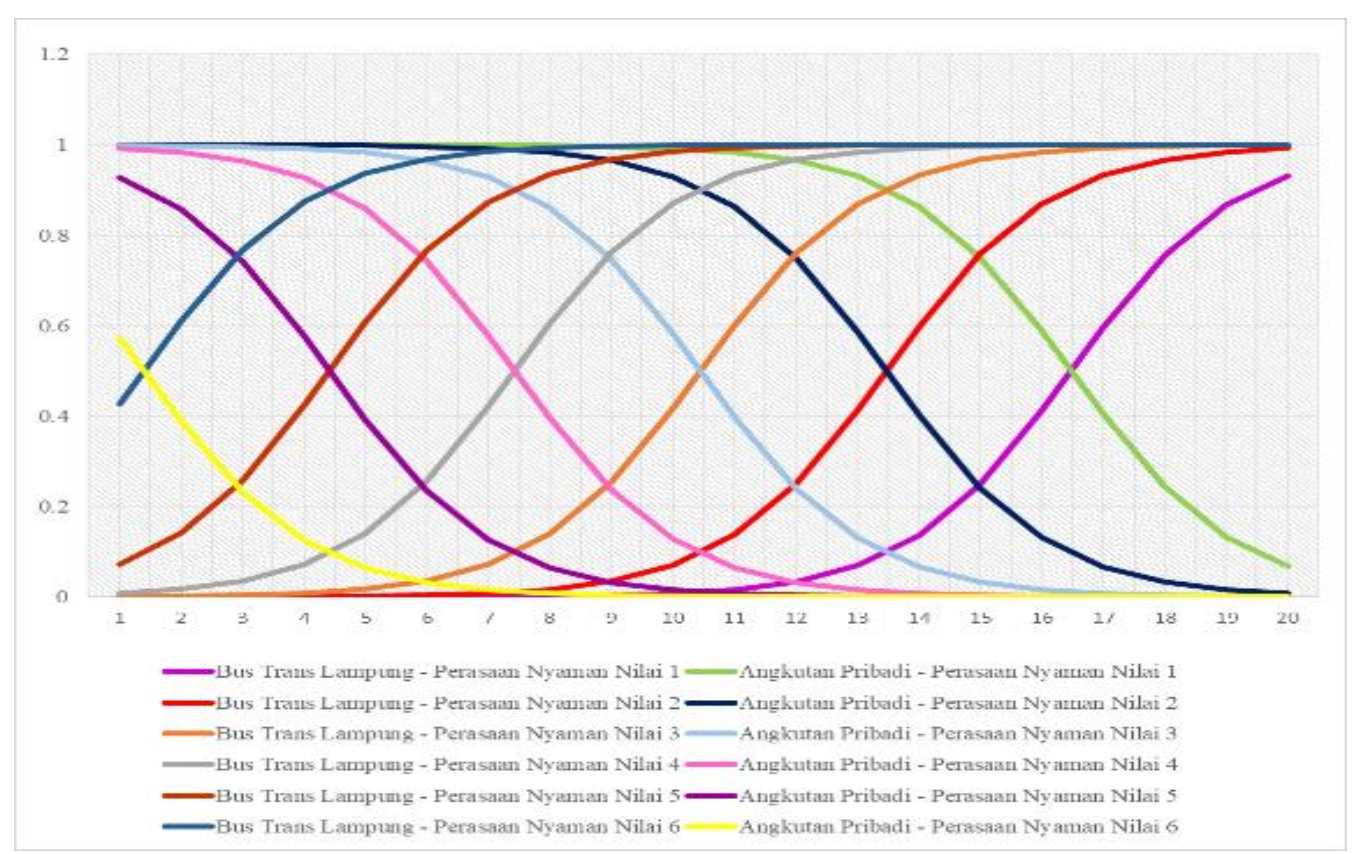

Sumber : Penulis, 2019

Gambar 3. Skenario Peluang Pemilihan Moda Angkutan Pribadi ke Moda Angkutan Umum Bus

Trans Lampung Akibat Perubahan Faktor Kenyamanan Terhadap Faktor Rit Perjalanan Bus.

Pada skenario pertama, diketahui bahwa ketika kenyamanan bernilai 1 , terdapat perpotongan pada nilai 17 yang artinya jika ingin membuat wisatawan bersedia menggunakan Bus Trans Lampung maka rit perjalanan yang dilakukan harus sangat banyak. Skenario kedua, ketika nilai kenyamanan bernilai 2 maka rit perjalanan bus yang harus disediakan oleh Bus Trans Lampung bernilai 14. Begitupun dengan skenarioskenario selanjutnya, dimana ketika kenyamanan terus ditingkatkan maka rit perjalanan bus yang diharapkan oleh wisatawan terjadi penurunan nilai. Skenario keempat merupakan skenario sensitivitas terakhir yang mendapakan nilai perpotongan. Ketika kenyamanan yang disediakan oleh Bus Trans Lampung bernilai 4 maka wisatawan bersedia menggunakan moda tersebut apabila rit perjalanan bus bernilai 8 .

Selanjutnya akan dilakukan perhitungan perubahan nilai pada faktor rit perjalanan bus terhadap kenyamanan untuk mengetahui peluang pergeseran yang akan terjadi. 
Berdasarkan analisis, didapatkan tiga skenario yaitu ketika ritasi bus bernilai 1, 2 dan 3 . Skenario sensitivitas tersebut menunjukkan bahwa ketika rit perjalanan bus bernilai 1 maka kenyamanan yang dibutuhkan agar wisatawan bersedia menggunakan moda angkutan umum Bus Trans Lampung yaitu bernilai 5. Ketika dilakukan perubahan faktor rit perjalanan bus menjadi bernilai 3, maka untuk membuat wisatawan bersedia menggunakan moda angkutan umum diperlukan rit perjalanan bernilai 3. Dapat disimpulkan bahwa semakin banyak rit perjalanan bus yang dilakukan maka nilai kenyamanan untuk membuat wisatawan bersedia menggunkan Bus Trans Lampung dapat semakin kecil.

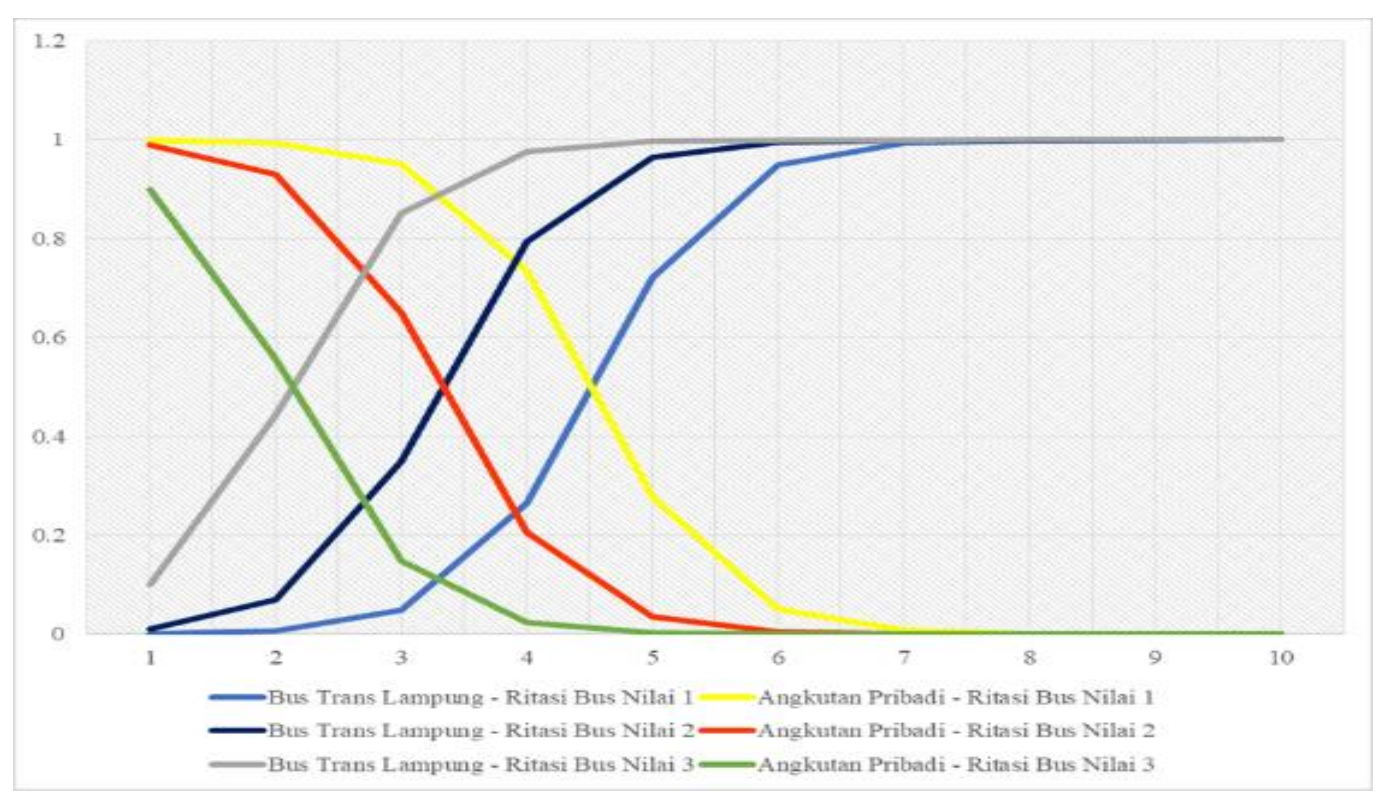

Sumber : Penulis, 2019

Gambar 4. Skenario Peluang Pemilihan Moda Angkutan Pribadi ke Moda Angkutan Umum Bus

Trans Lampung Akibat Perubahan Faktor Kenyamanan Terhadap Faktor Rit Perjalanan Bus

Berdasarkan skenario sensitivitas di atas maka rekomendasi pengoptimalan yang dapat disusun yaitu dengan cara meningkatkan faktor kenyamanan dan rit perjalanan bus. Hal tersebut karena kedua faktor tersebut merupakan faktor yang paling berpengaruh dalam pemilihan moda angkutan umum berdasarkan preferensi wisatawan itu sendiri. Namun dalam praktiknya, dalam perencanaan pasti terdapat beberapa hal yang dijadikan pertimbangan yang merupakan keterbatasan dalam sumber daya yang dimiliki. Oleh karena itu, jika terdapat keterbatasan maka hal yang dapat dilakukan adalah melakukan perbaikan pada salah satu faktor yang paling membutuhkan perbaikan. Faktor tersebut dapat diketahui jika dilihat dari tingkat sensitivitas yang sudah di uji antar faktor pengaruh.

Berdasarkan analisis sensitivitas yang sudah dilakukan, faktor kenyamanan merupakan faktor yang memiliki tingkat sensitivitas lebih tinggi dibandingkan faktor rit perjalanan bus. Semakin tinggi sensitivitas yang didapatkan oleh faktor maka semakin besar juga pengaruh yang akan diberikan kepada faktor lainnya. Oleh karena itu, rekomendasi pengoptimalan yang diberikan dalam penelitian ini yaitu dengan 
meningkatkan faktor kenyamanan untuk menarik minat wisatawan menggunakan moda angkutan pribadi. Hal tersebut relevan jika dibandingkan dengan meningkatkan faktor rit perjalanan, karena untuk meningkatkan rit perjalanan bus maka perlu diperhitungkannya juga biaya yang harus dikeluarkan. Rit perjalanan bus bekaitan dengan biaya operasional dan beberapa hal yang meliputi jumlah armada yang akan disediakan, jumlah penumpang yang menaiki bus pada sekali rit perjalanan, jarak menuju tempat wisata dari titik keberangkatan, biaya bahan bakar yang dikeluarkan dan sebagainya. Oleh karena itu peningkatan rit bus bukan merupakan rekomendasi untuk mengoptimalkan minat wisatawan dalam menggunakan moda angkutan umum Bus Trans Lampung.

Berbeda hal nya jika faktor kenyamanan yang ditingkatkan. Kenyamanan memang merupakan sesuatu yang sifat penilaiannya subjektif dan objektif. Namun menurut Gray:1979 yang menyebutkan bahwa kenyamanan dapat meliputi kenyamanan fisik penumpang, keindahan dan lingkungan. Kenyamanan fisik penumpang merupakan kenyamanan yang dirasakan oleh penumpang ketika berada di dalam kendaraan maupun ditempat pemberhentian, seperti misalnya kenyamanan tempat duduk atau tempat berdiri, kemudahan pada waktu masuk dan keluar kendaraan, tempat meletakkan barang dan sebagainya. Keindahan dapat berupa tempat duduk yang bersih atau tempat pemberhentian yang menarik. Sedangkan lingkungan meliputi suasana yang dirasakan ketika berada di dalam kendaraan, seperti misalnya lingkungan yang tenang karena tidak adanya pengamen yang masuk ke dalam kendaraan sehingga tidak menyebabkan polusi suara. Kenyamanan menurut Dirjen Perhubungan Darat menerangkan bahwa kenyamanan dapat berarti sesuatu yang berkaitan dengan ketersediaan tempat duduk, perlindungan dari cuaca, serta memiliki sirkulasi yang baik.

Karenanya jika terdapat keterbatasan biaya dalam operasionalnya, maka faktor kenyamanan yang harus telebih dahulu ditingkatkan agar sesuai dengan apa yang diharapkan oleh wisatawan. Sehingga wisatawan bersedia menggunakan Bus Trans Lampung sebagai transportasi wisata. Namun bukan berarti rit perjalanan bus yang dapat disediakan mengalami penurunan. Kenyamanan ditingkatkan dengan asumsi bahwa rit perjalanan bus yang sudah ada saat ini berjumlah 3 sudah cukup untuk mengakomodir wisatawan yang ingin melakukan kunjungan wisata. Berbeda hasilnya jika rit perjalanan yang nantinya akan disediakan mengalami penurunan jumlah, misalnya menjadi satu atau dua rit dalam sehari. Maka preferensi wisatawan terhadap kenyamanan akan memiliki nilai yang lebih tinggi dari sebelumnya. Oleh karena itu, rekomendasi pengoptimalan yang akan dilakukan pada faktor kenyamanan terlebih dahulu, dilakukan dengan syarat rit perjalanan bus yang ada tetap seperti saat ini (berjumlah 3). Rit perjalanan bus berjumlah 3 yang ada saat ini dinilai masih dapat mengakomodir wisatawan yang ada.

\section{SIMPULAN DAN SARAN}

Berdasarkan hasil analisis dan pembahasan di atas, maka didapatkan beberapa temuan studi yaitu:

1. Terdapat dua faktor yang paling memengaruhi wisatawan untuk bersedia beralih menggunakan moda angkutan umum Bus Trans Lampung, yaitu faktor kenyamanan dan rit perjalanan bus. 
2. Skenario sensitivitas yang didapatkan pada faktor kenyamanan terhadap rit perjalanan bus adalah enam, sedangkan sensitivitas yang didapatkan pada faktor rit perjalanan bus terhadap kenyamanan adalah tiga.

3. Faktor kenyamanan memiliki sensitivitas yang lebih tinggi dibandingkan dengan rit perjalanan bus, oleh karena itu rekomendasi pengoptimalan yang diberikan yaitu dengan cara meningkatkan faktor kenyamanan terlebih dahulu.

\section{DAFTAR PUSTAKA}

[1] Anggoman, J. P. 2007. Studi Tingkat Pelayanan Moda Angkutan Umum Damri di Kota Manado. Tesis.

[2] Basuki, A. T. 2015. Bahan Ajar Ekonometrika. Universitas Muhammadiyah.

[3] Kurniati, Y. F. 2001. Model Regregi Logistik Untuk Analisis Data Biner. Skripsi.

[4] Lesatri, Suthanaya, \& Wedagama. 2017. Perencanaan Sistem Operasional Angkutan Wisata Di Kota Denpasar. Jurnal Spektran. 64 - 70.

[5] Melati, F. 2018. Analisis Strategi Dinas Pariwisata Kabupaten Pesawaran Provinsi Lampung Dalam Mengembangkan Objek Wisata Di Pantai Sari Ringgung. Tesis.

[6] Putri, F. L. 2018. Kajian Pelayanan Moda Angkutan Umum Bus Trans Lampung Rute Unila - Itera Terhadap Civitas Akademika Itera. Tugas Akhir.

[7] Rahman, R. 2009. Studi Pemilihan Moda Angkutan Umum Antar Kota Menggunakan Metode Stated Preference. Jurnal SMARTEK. Vol 7, No. 4. November. 229-243.

[8] Saputra, Adian. 2017. Trans Lampung Utama Tawarkan Layanan Bus dan Taksi Harga Terjangkau dan Nyaman.

[9] Setiadi, I. B. 2015. Potensi Angkutan Umum Pariwisata Di Daerah Istimewa Yogyakarta. FSTPT International Symposium. Bandar Lampung: Unila.

[10] Sulistyorini, R. 2014. Perencanaan dan Permodelan Transportasi. Bandar Lampung: Garaha Ilmu.

[11] Tambunan, N. 2009. Posisi Transportasi Dalam Pariwisata. Majalah Ilmiah Panorama Nusantara, Edisi VI. Januari -Juni.

[12] Tamin, O. Z. 2008. Perencanaan, Permodelan, \& Rekayasa Transportasi. Bandung: ITB. 